\title{
Host Innate Immunity against Hepatitis E Virus and Viral Evasion Mechanisms
}

\author{
Sangmin Kang and Jinjong Myoung* \\ Korea Zoonosis Research Institute, Chonbuk National University, Iksan 54531, Republic of Korea
}

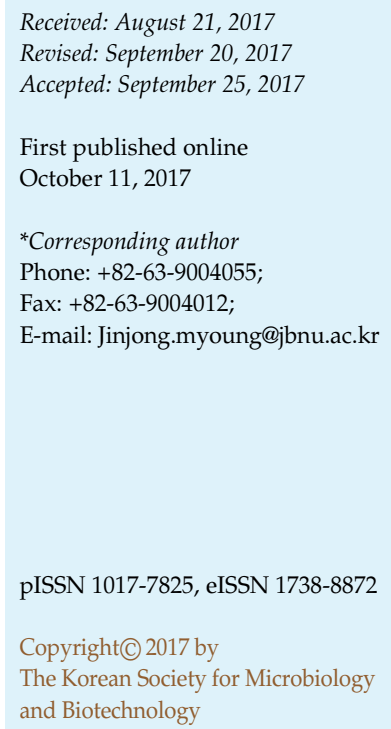

\begin{abstract}
Hepatitis E virus (HEV) infections cause epidemic or sporadic acute hepatitis, which are mostly self-limiting. However, viral infection in immunocompromised patients and pregnant women may result in serious consequences, such as chronic hepatitis and liver damage, mortality of the latter of which reaches up to 20-30\%. Type I interferon (IFN)-induced antiviral immunity is known to be the first-line defense against virus infection. Upon HEV infection in the cell, the virus genome is recognized by pathogen recognition receptors, leading to rapid activation of intracellular signaling cascades. Expression of type I IFN triggers induction of a barrage of IFN-stimulated genes, helping the cells cope with viral infection. Interestingly, some of the HEV-encoded genes seem to be involved in disrupting signaling cascades for antiviral immune responses, and thus crippling cytokine/chemokine production. Antagonistic mechanisms of type I IFN responses by HEV have only recently begun to emerge, and in this review, we summarize known HEV evasion strategies and compare them with those of other hepatitis viruses.
\end{abstract}

Keywords: Hepatitis E virus, immune evasion, innate immunity, interferon

\section{Introduction}

The hepatitis E virus (HEV) is one of the major causes of viral hepatitis. According to the World Health Organization, 20 million people are infected with HEV worldwide. Acute self-limiting hepatitis, frequent epidemic occurrence, and a high mortality rate in affected pregnant women (20-30\%) are hallmarks of hepatitis E infection [1]. HEV variants are classified into seven genotypes (GT 1-7) and all are members of the recently suggested species Orthohepevirus A of the Orthohepevirus genus [2, 3]. Among the seven genotypes, GT 1-4 have been associated with human infections. GT1 and GT2 infections, predominantly occurring in developing countries, are known to be restricted only to humans and non-human primates. On the contrary, GT3 and GT4 are transmitted zoonotically from pigs, deers, and wild boars in developed countries [4,5], which accounts for a majority of HEV outbreaks and sporadic cases in the area. On the other hand, GT5 and GT6 were discovered in wild boar and GT7 was isolated from camel. However, their zoonotic potential is not yet known.
$\mathrm{HEV}$ is a non-enveloped virus with a positive-sense single-stranded RNA genome. The $7.2 \mathrm{~kb}$ genome is capped and consists of the $5^{\prime}$ untranslated region (UTR), three open reading frames (ORFs 1-3), and the 3' UTR followed by poly A [6-8]. ORF1 encodes seven nonstructural (NS) proteins, including methyltransferase, $\mathrm{Y}$-domain, papain-like cysteine protease, hypervariable region (HVR), X-domain, RNA helicase, and RNA-dependent RNA polymerase (RdRp) [9-11], which are involved in viral genome replication and protein processing. ORF2 encodes the viral capsid protein, which plays an important role in binding to cells, viral assembly, and regulation of host immune responses [1214]. ORF3 encodes the small protein of 113 or 114 amino acids, which is necessary for virion release from infected cells [15-18]. HEV genotype 1 was reported to express another gene, ORF4, upon endoplasmic reticulum stress. ORF4 protein was shown to interact with multiple viral proteins, stimulating viral RdRp activity [19].

$\mathrm{HEV}$ infection induces innate immune responses in cells mainly through pathogen recognition receptors (PRRs), including retinoic-acid-inducible gene I (RIG-I)-like receptors 
and Toll-like receptors (TLRs) [20, 21]. Upon recognition of viral RNAs, those receptors activate downstream signal cascades, involving various signaling molecules such as mitochondrial antiviral-signaling protein (MAVS) [22-24], TIR-domain-containing adapter-inducing interferon- $\beta$ (TRIF) $[25,26]$, I kappa B kinase epsilon (IKKe)/TANKbinding kinase 1 (TBK1) [27-29], interferon regulatory factor 3 (IRF3) , IRF7 [30-36], and nuclear factor kappalight-chain-enhancer of activated B cells (NF- $\mathrm{B})$ [23, 37, 38]. Activation of those factors leads to expression of type I IFNs and IFN-stimulated genes (ISGs), which mount antiviral immune responses in infected cells and uninfected neighboring cells as well as mobilization of adaptive immune responses.

Interestingly, cells, chimpanzees, and human subjects infected by HEV display notable virus survival in the presence of sustained IFN responses, indicating that HEV may encode potent immune evasion strategies [39]. However, the lack of efficient HEV cell culture and small animal models has greatly hampered detailed analysis of the mechanisms of viral immune evasion strategies. In this comprehensive review, we provide current understanding of type I IFN-induced antiviral immune responses against HEV infection and viral evasion mechanisms for survival and replication.

\section{Type I IFN-Induced Antiviral Immunity in HEV Infection}

Type I IFN-induced antiviral immunity is the first line of defense against virus infection in cells. A large subgroup of molecules comprise human type I IFNs depending on their effects on cellular functions, mainly IFN- $\alpha$ and IFN- $\beta$, IFN$\varepsilon$, IFN- $\kappa$, IFN- $\omega$, and IFN- $\nu$ and other molecules [40-42]. IFN- $\alpha$ and IFN- $\beta$ have antiviral activities, counteracting viral infection and replication in infected cells and also activating other immune cells, such as natural killer cells, dendritic cells, and Kupffer cells [43-47].

During HEV infection, recognition of viral RNAs by PRRs triggers activation of downstream signaling molecules, leading to expression of type I IFNs and a myriad of ISGs [20, 48, 49]. RNA recognition receptors, such as RIG-I, melanoma differentiation-associated protein 5 (MDA5), and Toll-like receptor 3 (TLR3), have been shown to elicit type I IFN production through different signaling cascades $[50,51]$ with RIG-I being a major specific sensor for viral dsRNA. RIG-I contains a RNA helicase-DEAD box and two repeats of caspase recruitment domain (CARD) for the recognition of the viral RNA and the recruitment of MAVS, respectively [52-54].

\section{RIG-I-Mediated Recognition of HEV Infection}

The transcription level of RIG-I was initially low, but increased markedly after $48-72 \mathrm{~h}$ upon HEV infection in human lung epithelial cells (A549), while levels of MDA5 and TLR3 were not changed [55]. Similarly, initial expression of IFN- $\beta$ was low, but significantly increased at $72 \mathrm{~h}$ post-infection. In addition, inflammatory cytokines and chemokines, such as chemokine (C-C motif) ligand 20 (CCL20), CCL5/RANTES, interleukin-6 (IL-6), IL-8, tumor necrosis factor alpha (TNF- $\alpha)$, TNF- $\alpha$ family member LTA, and TNF-related apoptosis-inducing ligand (TRAIL)/TNF superfamily member 10 (TNFSF10) were upregulated in HEV-infected A549 cells. Of note, expression of IL-6 and RANTES was dampened by the silencing of myeloid differentiation primary response gene 88 (MyD88), but not by that of TRIF. As TLR7 induces NF- $\kappa$ B activation through MyD88, but not TRIF, these data suggest that TLR7 is involved in recognition of the viral RNA and triggering of NF-кB-dependent cytokine production [55].

Subsequent studies showed that ORF3 is responsible for transcriptional activation of IFN- $\beta$ through upregulation of expression and activity of RIG-I (Fig. 1) [56]. Interestingly, ectopic expression of ORF3 enhanced K63-linked ubiquitination by interaction with the N-terminal CARD of RIG-I, which was mediated by two ubiquitin ligases, tripartite motif-containing protein 25 (TRIM25) and Riplet/ Ring finger protein 135 (RNF135). Ubiquitination-mediated RIG-I activation leads to its interaction with MAVS on the mitochondria, activating downstream signaling cascades $[57,58]$. Domain mapping of ORF3 demonstrated that the C-terminal domain of ORF3 was sufficient for the activation of RIG-I signaling. Furthermore, analysis of the ubiquitination activity of ORF3 cloned from four HEV genotypes showed that GT1- and GT3-derived ORF3 activated RIG-I-mediated IFN expression at comparable levels, whereas that of GT2 and GT4 had a negligible effect, suggesting that ORF3mediated IFN induction is genotype-specific [59]. Molecular differences among HEV genotypes remain largely unknown. GT1 and GT2 HEV infect only humans and non-human primates and GT3 and GT4 infect both humans and animals. However, what factors are involved in differential host tropisms of various HEV genotypes remains an open question. It is noteworthy to mention that analysis of a cell culture-adapted GT3 strain of HEV (Kernow-C1) isolated from feces of an HIV-1/HEV co-infected patient indicated 
integration of the host S17 ribosomal RNA sequence in the HVR of the HEV genome [60]. Furthermore, HEV replication efficacy was increased by S17 insertion into the HEV RNA genome in cell culture using an infectious cDNA clone [61, 62]. Similarly, the host $S 19$ ribosomal protein sequence integrated in the HEV RNA, an insertion that was previously found in HEV from the serum of a liver transplant patient, only partially improved viral growth in cell culture [63], suggesting that the sequence of an insert may be important for viral replication in vitro. Taken together, these results suggest that genotype-specific variations may have important implications in the host tropisms of HEV. Elucidation of detailed molecular differences in the genome sequences of various HEV genotypes and strains await further scrutiny. Of note, RIG-I seems to stimulate type I IFN responses upon HEV infection both through canonical and noncanonical signaling pathways, as RIG-I-mediated ISG expression could also be independent of IRF3 and IRF7 activation [59]. HEV replication efficacy was inversely correlated with levels of RIG-I as shown by both gain- and loss-of-function studies in Huh7.5, A549, and HepaRG cells. As a result, ISG expression, but not that of IFN, was accordingly regulated.

It is interesting to note that RIG-I-mediated antiviral responses play a major role in $\mathrm{HCV}$ infection in a similar manner. Recognition of the polyuridine motif of the $3^{\prime} \mathrm{UTR}$ of the HCV RNA genome by RIG-I triggers expression of IFNs and ISGs, counteracting viral replication in cells [64]. Therefore, levels of RIG-I protein are closely correlated with those of type I IFN induction in a particular cell type. In hepatoma cell lines, such as Huh7 and Huh7.5, endogenous levels of RIG-I are low owing to mutations. Thus, IFN induction is largely defective. Cells with substantial RIG-I expression, such as LH86 cells, can mount sufficient innate immunity against $\mathrm{HCV}$ infection to suppress viral replication $[65,66]$. In fact, it was shown that the expression level of RIG-I in LH86 is comparable to that in primary hepatocytes. These results attest to the importance of RIG-I in the induction and activation of antiviral immune responses to liver-tropic viruses, such as $\mathrm{HEV}$ and $\mathrm{HCV}$.

\section{HEV-Mediated IRF Activation}

During virus infection, IRF1 serves as a strong transcriptional regulator in the IFN signaling network. Overexpression of IRF1 effectively inhibited HEV replication in a Huh7-based p6-luc replicon as well as a full-length infectious model (Fig. 1) [67]. It was shown that antiviral immune effects of IRF1 were comparable to those of high- dose recombinant IFN- $\alpha(1,000 \mathrm{U} / \mathrm{ml})$ treatment on HEVharboring cells. Interestingly, IRF1 did not trigger IFN $-\alpha,-\beta$, and $-\gamma$ gene expression in Huh7, HepaRG, A549, and MRC-5 cells. Moreover, the expression level of IRF1 mRNA was not increased by treatment with recombinant IFN- $\alpha$. Thus, IRF1 may not be involved in induction of IFN nor a target of IFN-regulated antiviral immune responses. Molecular analyses showed that IRF1 binds to the signal transducer and activator of transcription 1 (STAT1) promoter region, driving transcription of STAT1, but not STAT2 and janus kinases (JAKs). As a result, levels of total and phosphorylated STAT1 proteins increase accordingly, stimulating induction of ISGs in hepatoma and non-hepatoma cells. In addition, when combined with ribavirin, IRF1 demonstrated higher ISG induction and stronger inhibition of HEV replication than ribavirin alone. These results suggest that modulation of IRF1 activity may provide an effective means to abate HEV replication and virus-induced pathologies.

IL-8 is a multifunctional proinflammatory chemokine produced mainly through activation of TLR signaling [68, 69]. Upon virus infection, IL-8 recruits immune cells, such as macrophages, neutrophils, and dendritic cells, to the site of infection, inducing phagocytosis, apoptosis, and cell death [70, 71]. HEV infection in Huh7 cells significantly upregulated the IL-8 promoter activity, and a HEVencoded ORF1 was subsequently shown to heighten IL-8 expression (Fig. 1) [55, 72]. ORF1-mediated IL-8 expression entails activation of activator protein 1 (AP-1), a transcription factor that regulates various cytokines and growth factors $[73,74]$. Other cytokines, such as IFN- $\beta$ and IFN- $\gamma$, displayed an antagonistic effect on the expression of IL-8 [75-77]. Analogously, HCV-encoded E2 and NS5A inhibited expression of IFN- $\beta$ and downstream ISGs through upregulation of IL-8 [78-80]. In addition, as shown in HEV infection, AP- 1 was required for IFN- $\beta$ gene transcription as it binds to the PRD IV element of the IFN- $\beta$ promoter, inducing assembly of IFN- $\beta$ enhanceosome [81]. However, the detailed mechanisms of IL- 8 and AP- 1 on IFN- $\beta$ expression remain largely elusive.

Several human hepatoma cell lines (Huh7, Huh7.5, and HepG2/C3A) display differential capacities to support HEV replication, likely due to varying levels of endogenous antiviral molecules, such as PRRs, IRFs, and ISGs. As shown by TaqMan Low Density Array, at early stages of HEV infection, HepG2/C3A cells express substantial levels of PRRs (RIG-I, IFIH1, and TLR3) and ISGs (ISG15, ISG20, ISG54, ISG56, IFN-induced GTP-binding protein MX1, 2'5 '-oligoadenylate synthetase 1 (OAS1), TRAIL, etc.) whereas Huh7.5 and S10-3 cells did not [82]. In fact, Huh7.5 cells 
contain a mutation in RIG-I, which might be responsible for the low levels of antiviral immune responses. When Huh7.5 cells were reconstituted with wild-type RIG-I, significant levels of RIG-I-mediated immune responses were observed, leading to inhibition of HEV replication. Furthermore, inhibition of TBK/IKK $\varepsilon$, downstream of RIG-I, suppressed IRF3-mediated type I IFN induction, enhancing HEV replication in HepG2/C3A cells [27, 83]. These data provide a hint on the crucial roles played by RIG-I-mediated sensing of the HEV RNA genome for the induction of antiviral immune responses and viral clearance.

When phosphorylated, IRF3 homodimerizes or heterodimerizes with IRF7, subsequently translocating into the nucleus and activating IFN- $\alpha / \beta$ production. Similarly, phosphorylation of NF- $\kappa$ B p65 on serine 468 and 536 is required for its nuclear translocation and induction of the type I IFNs [84, 85]. Phosphorylation of IRF3 and NF-кB p65 requires, in turn, autophosphorylation of upstream kinases (TBK1 and IKK $\varepsilon$ ) on serine 172. The importance of TBK1 S172 phosphorylation in the induction of type I IFNs was highlighted when a RIG-I-specific inhibitor (BX795) was employed. BX795 treatment blocked RIG-I activation, leading to impairment of TBK1 S172 phosphoryaton and subsequent IFN expression. In contrast, acitretin, a synthetic retinoid approved by the US Food and Drug Administration, functions as an agonist of RIG-I signaling and was shown to induce preferential apoptosis of HIVinfected cells [86-88]. It would be intriguing to examine if acitretin has similar therapeutic effects on HEV infection in vitro and in vivo.

\section{HEV Evasion of Type I IFN-Induced Antiviral Immunity}

Many pathogenic viruses have evolved molecular evasion mechanisms to escape the host immune defense in direct and indirect manners. For example, HCV encodes several proteins, such as core, E2, NS3/4A, NS4B, and NS5A, to incapacitate host immune responses (Fig. 1) [89, 90]. Those immune regulators are believed to play pivotal roles in the development of drug resistance and chronic infection induced by HCV (cirrhosis and/or liver cancer). In the case of HEV infections, the majority of them are self-limiting and acute infections and are quickly resolved in healthy subjects. However, in immunocompromised patients, HEV infection may progress to chronic phases, inducing persistent hepatitis and liver damage. These data suggest that immune responses are an important determinant of outcomes of HEV infection, and its genome may likely encode antagonists and/or modulators of host immune responses.

In this regard, it is interesting to note that IFN- $\alpha$ treatment only partially inhibited HEV replication, whereas it markedly blunted that of HCV in vitro and in vivo, implying for HEV-encoded antagonists of IFN- $\alpha$-mediated antiviral immunity [91]. In addition, other IFNs, such as IFN- $\beta,-\gamma$, and $\lambda 1, \lambda 2$, and $\lambda 3$, had little, if any, suppressive effect on HEV replication, highlighting the importance of IFN- $\alpha$ in the antiviral immunity. This notion was corroborated by the observations that silencing of STAT1 and IRF9 resulted in significant increase of the HEV RNA levels in cells. Furthermore, IFN- $\alpha$-induced STAT1 phosphorylation and subsequent ISG expression were significantly decreased upon HEV infection in A549 cells [92] at early time points (15-30 min), while those of JAK1, tyrosine kinase 2, and STAT2 were unchanged. These data suggest that HEV encodes strong IFN- $\alpha$ antagonists in its genome. In fact, HEV ORF3 protein interacts with STAT1 as shown by co-immunoprecipitation assay, impairing IFN$\alpha$-induced STAT1 phosphorylation and down-modulation of ISGs, PKR, 2',5'-OAS, and MxA (Fig. 1). These observations are analogous to those in $\mathrm{HCV}$ infections, as $\mathrm{HCV}$ core protein also downregulates IFN signaling by the inhibition of STAT1 tyrosine phosphorylation and its dimerization with STAT2 [92]. In addition, HCV core protein suppresses activation of the JAK-STAT pathway by induction of suppressor of cytokine signaling 3 in HepG2 cells [93], a powerful inhibitor of JAK-STAT signaling [94, 95]. Moreover, ORF3 protein (HEV GT4) inhibited IFN- $\beta$ gene expression in poly I:C-stimulated A549 cells by upregulation of signal regulatory protein-alpha, a cell transmembrane glycoprotein known to be involved in the negative regulation of innate immunity (Fig. 1) [96]. Some of the nonstructural proteins encoded by HEV emerge as potential IFN antagonists as well. When the ORF1 of HEV was expressed in the absence of ORF2 and ORF3 expression in S10-3 cells, poly I:Cinduced IFN- $\beta$ expression was notably inhibited [97], which was likely due to the reduction of IRF3 phosphorylation and activation. Molecular analyses indicated that PCP and HPX protein are responsible for the ORF1-mediated inhibition of type I IFN-induced antiviral immunity. PCP is a papain-like cysteine protease, responsible for proteolytic cleavage of the ORF1 polyprotein. Mutation of the catalytic domain, cysteine 1152 of PCP, deprived its proteolytic activity, blocking ORF1 processing. However, recent studies have shown that PCP plays important roles in the modulation of host immune responses as well. It is intriguing to note that PCP carried out deISGylation of the ISG15-conjugated 


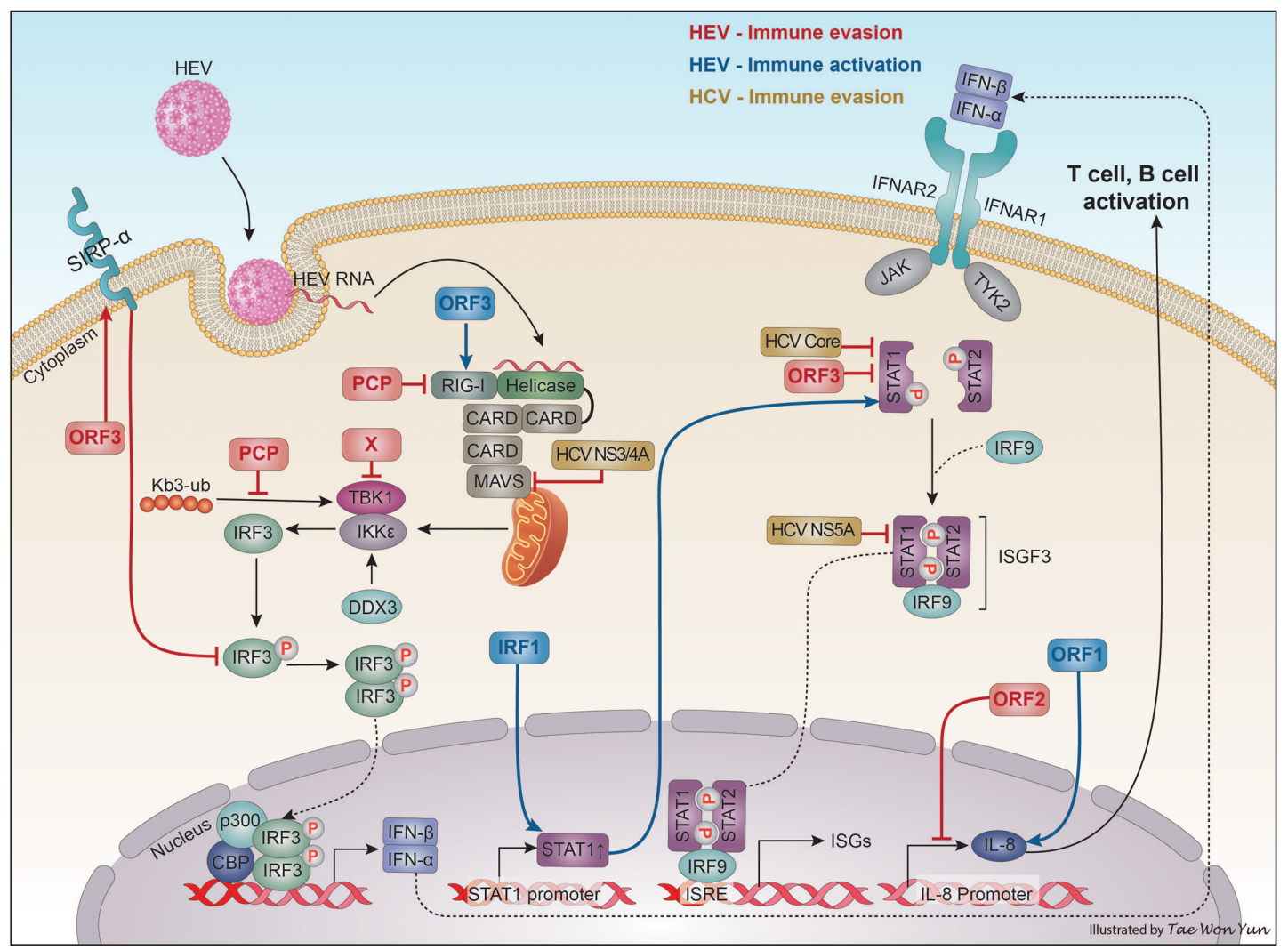

Fig. 1. Activation and evasion of innate immune responses by hepatitis E virus (HEV).

Upon HEV infection, the viral genome is recognized by pattern recognition receptors (PRRs), such as retinoic-inducible gene-I (RIG-I), melanoma differentiation-associated protein 5 (MDA5), and Toll-like receptor 3 (TLR3), subsequently triggering activation of type I interferon (IFN) signaling cascades. IFN regulatory factor 1 (IRF1) restricts HEV replication by activating STAT1 and IFN-stimulated gene (ISG) expression after HEV infection. In addition, HEV ORF3 induces RIG-I expression and its activation by interacting with the RIG-I N-terminal domain. HEV has evolved molecular evasion mechanisms to escape the host immune defense in direct or indirect manners. (i) HEV papain-like cysteine protease (PCP) inhibits RIG-I and TANK-binding kinase 1 (TBK1)-induced IFN- $\beta$ induction by downregulating K63-linked ubiquitination. (ii) HEV $X$ protein inhibits TBK1-induced IRF3 phosphorylation. (iii) HEV ORF3 protein activates signal regulator protein alpha (SIRP- $\alpha$ ) to highjack the negative feedback mechanism of innate immune responses, suppressing IRF3 phosphorylation. (iv) ORF3 also inhibits IFN- $\alpha$-induced STAT1 phosphorylation and ISG expression. HCV-encoded immune evasion mechanisms are also indicated.

cellular proteins, presumably by its deubiquitination activity [98-100]. Furthermore, the deubiquitinase activity of PCP mediates deubiquitination of RIG-I and TBK1 (Fig. 1) [97, 98], the ubiquitination of which is crucial for IRF3 phosphorylation and subsequent IFN- $\beta$ expression. PCP protein from severe acute respiratory syndrome coronavirus has deubiquitinating enzyme activity as well [101]. These data provide compelling evidence that HEV PCP protein functions as a powerful antagonist of type I IFN-induced antiviral immunity.

Last but not least, HPX also exhibits immunomodulatory activity, which consists of three putative domains: HVR, Pro, and X. Ectopic expression of HPX inhibited poly I:Cinduced activation of RIG-I, MDA5, TBK1, and IKK $\varepsilon$ [97].
In addition, poly I:C-induced IRF3 phosphorylation was also decreased by HPX protein (Fig. 1). Individual expression of the three domains of HPX showed that $\mathrm{X}$ domain was responsbile for HPX-mediated inhibition of cellular antiviral immunity.

In conclusion, since its dicovery over 30 years ago, HEV infection-related pathology has presented itself as one of the major causes of hepatitis, affecting more than 20 million people annually. However, virus-specific therapeutics and preventive vaccines are still elusive. The lack of efficient cell culture and small animal models has greatly hampered detailed analysis of viral replication mechanisms and hostpathogen interactions. Emerging data from available cell culture models and infectious molecular clones strongly 
suggest that several viral proteins are involved in HEV evasion of type I IFN-induced antiviral immune responses. Further studies are required to understand HEV-induced pathobiology by improving an efficient cell culture system and/or a small animal model.

\section{Acknowledgments}

This work was supported by a grant from the Korea Health Technology R\&D Project through the Korea Health Industry Development Institute (KHIDI), funded by the Ministry of Health \& Welfare, Republic of Korea (Grant No. HI16C0973).

\section{References}

1. Jameel S. 1999. Molecular biology and pathogenesis of hepatitis E virus. Expert Rev. Mol. Med. 1999: 1-16.

2. Smith DB, Purdy MA, Simmonds P. 2013. Genetic variability and the classification of hepatitis E virus. J. Virol. 87: 41614169.

3. Sridhar S, Teng JLL, Chiu TH, Lau SKP, Woo PCY. 2017. Hepatitis $\mathrm{E}$ virus genotypes and evolution: emergence of camel hepatitis E variants. Int. J. Mol. Sci. 18: E869.

4. Pavio N, Meng XJ, Doceul V. 2015. Zoonotic origin of hepatitis E. Curr. Opin. Virol. 10: 34-41.

5. Meng XJ. 2010. Hepatitis E virus: animal reservoirs and zoonotic risk. Vet. Microbiol. 140: 256-265.

6. Tam AW, Smith MM, Guerra ME, Huang CC, Bradley DW, Fry KE, et al. 1991. Hepatitis E virus (HEV): molecular cloning and sequencing of the full-length viral genome. Virology 185: 120-131.

7. Graff J, Torian U, Nguyen H, Emerson SU. 2006. A bicistronic subgenomic mRNA encodes both the ORF2 and ORF3 proteins of hepatitis E virus. J. Virol. 80: 5919-5926.

8. Kabrane-Lazizi Y, Fine JB, Elm J, Glass GE, Higa H, Diwan A, et al. 1999. Evidence for widespread infection of wild rats with hepatitis E virus in the United States. Am. J. Trop. Med. Hyg. 61: 331-335.

9. Ropp SL, Tam AW, Beames B, Purdy M, Frey TK. 2000. Expression of the hepatitis E virus ORF1. Arch. Virol. 145: 1321-1337.

10. Sehgal D, Thomas S, Chakraborty M, Jameel S. 2006. Expression and processing of the hepatitis E virus ORF1 nonstructural polyprotein. Virol. J. 3: 38.

11. Suppiah S, Zhou Y, Frey TK. 2011. Lack of processing of the expressed ORF1 gene product of hepatitis $\mathrm{E}$ virus. Virol. J. 8: 245.

12. Graff J, Zhou YH, Torian U, Nguyen H, St Claire M, Yu C, et al. 2008. Mutations within potential glycosylation sites in the capsid protein of hepatitis E virus prevent the formation of infectious virus particles. J. Virol. 82: 1185-1194.
13. Qi Y, Zhang F, Zhang L, Harrison TJ, Huang W, Zhao C, et al. 2015. Hepatitis E virus produced from cell culture has a lipid envelope. PLoS One 10: e0132503.

14. Shiota T, Li TC, Yoshizaki S, Kato T, Wakita T, Ishii K. 2013. The hepatitis $\mathrm{E}$ virus capsid C-terminal region is essential for the viral life cycle: implication for viral genome encapsidation and particle stabilization. J. Virol. 87: 6031-6036.

15. Takahashi M, Yamada K, Hoshino Y, Takahashi H, Ichiyama K, Tanaka T, et al. 2008. Monoclonal antibodies raised against the ORF3 protein of hepatitis E virus (HEV) can capture HEV particles in culture supernatant and serum but not those in feces. Arch. Virol. 153: 1703-1713.

16. Yamada K, Takahashi M, Hoshino Y, Takahashi H, Ichiyama K, Nagashima S, et al. 2009. ORF3 protein of hepatitis $\mathrm{E}$ virus is essential for virion release from infected cells. J. Gen. Virol. 90: 1880-1891.

17. Nagashima S, Takahashi M, Jirintai, Tanaka T, Yamada $K$, Nishizawa T, et al. 2011. A PSAP motif in the ORF3 protein of hepatitis E virus is necessary for virion release from infected cells. J. Gen. Virol. 92: 269-278.

18. Kenney SP, Pudupakam RS, Huang YW, Pierson FW, LeRoith T, Meng XJ. 2012. The PSAP motif within the ORF3 protein of an avian strain of the hepatitis $E$ virus is not critical for viral infectivity in vivo but plays a role in virus release. J. Virol. 86: 5637-5646.

19. Nair VP, Anang S, Subramani C, Madhvi A, Bakshi K, Srivastava A, et al. 2016. Endoplasmic reticulum stress induced synthesis of a novel viral factor mediates efficient replication of genotype-1 hepatitis E virus. PLoS Pathog. 12: e1005521.

20. Akira S, Uematsu S, Takeuchi O. 2006. Pathogen recognition and innate immunity. Cell 124: 783-801.

21. Medzhitov R. 2007. Recognition of microorganisms and activation of the immune response. Nature 449: 819-826.

22. Kawai T, Takahashi K, Sato S, Coban C, Kumar H, Kato H, et al. 2005. IPS-1, an adaptor triggering RIG-I- and Mda5mediated type I interferon induction. Nat. Immunol. 6: 981-988.

23. Seth RB, Sun L, Ea CK, Chen ZJ. 2005. Identification and characterization of MAVS, a mitochondrial antiviral signaling protein that activates NF-kappaB and IRF 3. Cell 122: 669-682.

24. Xu LG, Wang YY, Han KJ, Li LY, Zhai Z, Shu HB. 2005. VISA is an adapter protein required for virus-triggered IFN-beta signaling. Mol. Cell 19: 727-740.

25. Hardy MP, McGettrick AF, O'Neill LA. 2004. Transcriptional regulation of the human TRIF (TIR domain-containing adaptor protein inducing interferon beta) gene. Biochem. J. 380: 83-93.

26. Yamamoto $M$, Sato $S$, Hemmi $H$, Hoshino $K$, Kaisho $T$, Sanjo H, et al. 2003. Role of adaptor TRIF in the MyD88independent Toll-like receptor signaling pathway. Science 301: 640-643.

27. Fitzgerald KA, McWhirter SM, Faia KL, Rowe DC, Latz E, 
Golenbock DT, et al. 2003. IKKepsilon and TBK1 are essential components of the IRF3 signaling pathway. Nat. Immunol. 4: 491-496.

28. Hacker H, Karin M. 2006. Regulation and function of IKK and IKK-related kinases. Sci. STKE 2006: re13.

29. Gatot JS, Gioia R, Chau TL, Patrascu F, Warnier M, Close P, et al. 2007. Lipopolysaccharide-mediated interferon regulatory factor activation involves TBK1-IKKepsilon-dependent Lys(63)-linked polyubiquitination and phosphorylation of TANK/I-TRAF. J. Biol. Chem. 282: 31131-31146.

30. Grandvaux N, Servant MJ, tenOever B, Sen GC, Balachandran S, Barber GN, et al. 2002. Transcriptional profiling of interferon regulatory factor 3 target genes: direct involvement in the regulation of interferon-stimulated genes. J. Virol. 76: 5532-5539.

31. Hiscott J. 2007. Triggering the innate antiviral response through IRF-3 activation. J. Biol. Chem. 282: 15325-15329.

32. Honda K, Taniguchi T. 2006. IRFs: master regulators of signalling by Toll-like receptors and cytosolic patternrecognition receptors. Nat. Rev. Immunol. 6: 644-658.

33. Yoneyama M, Suhara W, Fukuhara Y, Fukuda M, Nishida E, Fujita T. 1998. Direct triggering of the type I interferon system by virus infection: activation of a transcription factor complex containing IRF-3 and CBP/p300. EMBO J. 17: 1087-1095.

34. Weaver BK, Kumar KP, Reich NC. 1998. Interferon regulatory factor 3 and CREB-binding protein/p300 are subunits of double-stranded RNA-activated transcription factor DRAF1. Mol. Cell. Biol. 18: 1359-1368.

35. Au WC, Yeow WS, Pitha PM. 2001. Analysis of functional domains of interferon regulatory factor 7 and its association with IRF-3. Virology 280: 273-282.

36. Honda K, Yanai $H$, Negishi $H$, Asagiri $M$, Sato $M$, Mizutani T, et al. 2005. IRF-7 is the master regulator of type-I interferon-dependent immune responses. Nature 434: 772-777.

37. Hiscott J, Grandvaux N, Sharma S, Tenoever BR, Servant MJ, Lin R. 2003. Convergence of the NF-kappaB and interferon signaling pathways in the regulation of antiviral defense and apoptosis. Ann. NY Acad. Sci. 1010: 237-248.

38. Wang J, Basagoudanavar $\mathrm{SH}$, Wang $\mathrm{X}$, Hopewell $\mathrm{E}$, Albrecht R, Garcia-Sastre A, et al. 2010. NF-kappa B RelA subunit is crucial for early IFN-beta expression and resistance to RNA virus replication. J. Immunol. 185: 1720-1729.

39. Yu C, Boon D, McDonald SL, Myers TG, Tomioka K, Nguyen H, et al. 2010. Pathogenesis of hepatitis E virus and hepatitis $C$ virus in chimpanzees: similarities and differences. J. Virol. 84: 11264-11278.

40. Hardy MP, Owczarek CM, Jermiin LS, Ejdeback M, Hertzog PJ. 2004. Characterization of the type I interferon locus and identification of novel genes. Genomics 84: 331-345.

41. Zitvogel L, Galluzzi L, Kepp O, Smyth MJ, Kroemer G. 2015. Type I interferons in anticancer immunity. Nat. Rev.
Immunol. 15: 405-414.

42. Xi Y, Day SL, Jackson RJ, Ranasinghe C. 2012. Role of novel type I interferon epsilon in viral infection and mucosal immunity. Mucosal Immunol. 5: 610-622.

43. Dunn GP, Bruce AT, Sheehan KC, Shankaran V, Uppaluri R, Bui JD, et al. 2005. A critical function for type I interferons in cancer immunoediting. Nat. Immunol. 6: 722-729.

44. Vilcek J. 2003. Novel interferons. Nat. Immunol. 4: 8-9.

45. Biron CA, Nguyen KB, Pien GC, Cousens LP, SalazarMather TP. 1999. Natural killer cells in antiviral defense: function and regulation by innate cytokines. Annu. Rev. Immunol. 17: 189-220.

46. Swann JB, Hayakawa Y, Zerafa N, Sheehan KC, Scott B, Schreiber RD, et al. 2007. Type I IFN contributes to NK cell homeostasis, activation, and antitumor function. J. Immunol. 178: $7540-7549$.

47. Asselin-Paturel C, Brizard G, Chemin K, Boonstra A, O'Garra A, Vicari A, et al. 2005. Type I interferon dependence of plasmacytoid dendritic cell activation and migration. J. Exp. Med. 201: 1157-1167.

48. Alexopoulou L, Holt AC, Medzhitov R, Flavell RA. 2001. Recognition of double-stranded RNA and activation of NFkappaB by Toll-like receptor 3. Nature 413: 732-738.

49. Schoggins JW, Wilson SJ, Panis M, Murphy MY, Jones CT, Bieniasz $\mathrm{P}$, et al. 2011. A diverse range of gene products are effectors of the type I interferon antiviral response. Nature 472: 481-485.

50. Nan Y, Nan G, Zhang YJ. 2014. Interferon induction by RNA viruses and antagonism by viral pathogens. Viruses 6: 4999-5027.

51. Noppert SJ, Fitzgerald KA, Hertzog PJ. 2007. The role of type I interferons in TLR responses. Immunol. Cell Biol. 85: 446-457.

52. Fujita T, Onoguchi K, Onomoto K, Hirai R, Yoneyama M. 2007. Triggering antiviral response by RIG-I-related RNA helicases. Biochimie 89: 754-760.

53. Yoneyama M, Kikuchi M, Natsukawa T, Shinobu N, Imaizumi T, Miyagishi M, et al. 2004. The RNA helicase RIG-I has an essential function in double-stranded RNAinduced innate antiviral responses. Nat. Immunol. 5: 730-737.

54. Nakhaei P, Genin P, Civas A, Hiscott J. 2009. RIG-I-like receptors: sensing and responding to RNA virus infection. Semin. Immunol. 21: 215-222.

55. Devhare PB, Chatterjee SN, Arankalle VA, Lole KS. 2013. Analysis of antiviral response in human epithelial cells infected with hepatitis E virus. PLoS One 8: e63793.

56. Nan Y, Ma Z, Wang R, Yu Y, Kannan H, Fredericksen B, et al. 2014. Enhancement of interferon induction by ORF3 product of hepatitis E virus. J. Virol. 88: 8696-8705.

57. Gack MU, Shin YC, Joo CH, Urano T, Liang C, Sun L, et al. 2007. TRIM25 RING-finger E3 ubiquitin ligase is essential for RIG-I-mediated antiviral activity. Nature 446: 916-920.

58. Oshiumi H, Miyashita M, Matsumoto M, Seya T. 2013. A 
distinct role of Riplet-mediated K63-linked polyubiquitination of the RIG-I repressor domain in human antiviral innate immune responses. PLoS Pathog. 9: e1003533.

59. Xu L, Wang W, Li Y, Zhou X, Yin Y, Wang Y, et al. 2017. RIG-I is a key antiviral interferon-stimulated gene against hepatitis E virus regardless of interferon production. Hepatology 65: 1823-1839.

60. Shukla P, Nguyen HT, Torian U, Engle RE, Faulk K, Dalton HR, et al. 2011. Cross-species infections of cultured cells by hepatitis $\mathrm{E}$ virus and discovery of an infectious virus-host recombinant. Proc. Natl. Acad. Sci. USA 108: 2438-2443.

61. Shukla P, Nguyen HT, Faulk K, Mather K, Torian U, Engle $\mathrm{RE}$, et al. 2012. Adaptation of a genotype 3 hepatitis $\mathrm{E}$ virus to efficient growth in cell culture depends on an inserted human gene segment acquired by recombination. J. Virol. 86: 5697-5707.

62. Kenney SP, Meng XJ. 2015. The lysine residues within the human ribosomal protein S17 sequence naturally inserted into the viral nonstructural protein of a unique strain of hepatitis E virus are important for enhanced virus replication. J. Virol. 89: 3793-3803.

63. Nguyen HT, Torian U, Faulk K, Mather K, Engle RE, Thompson E, et al. 2012. A naturally occurring human/ hepatitis $\mathrm{E}$ recombinant virus predominates in serum but not in faeces of a chronic hepatitis $\mathrm{E}$ patient and has a growth advantage in cell culture. J. Gen. Virol. 93: 526-530.

64. Saito T, Owen DM, Jiang F, Marcotrigiano J, Gale M Jr. 2008. Innate immunity induced by composition-dependent RIG-I recognition of hepatitis C virus RNA. Nature 454: 523-527.

65. Zhu H, Dong H, Eksioglu E, Hemming A, Cao M, Crawford JM, et al. 2007. Hepatitis C virus triggers apoptosis of a newly developed hepatoma cell line through antiviral defense system. Gastroenterology 133: 1649-1659.

66. Eksioglu EA, Zhu H, Bayouth L, Bess J, Liu HY, Nelson DR, et al. 2011. Characterization of HCV interactions with Toll-like receptors and RIG-I in liver cells. PLoS One 6: e21186.

67. Xu L, Zhou X, Wang W, Wang Y, Yin Y, Laan LJ, et al. 2016. IFN regulatory factor 1 restricts hepatitis $E$ virus replication by activating STAT1 to induce antiviral IFNstimulated genes. FASEB J. 30: 3352-3367.

68. Ghasemi H, Ghazanfari T, Yaraee R, Faghihzadeh S, Hassan ZM. 2011. Roles of IL-8 in ocular inflammations: a review. Ocul. Immunol. Inflamm. 19: 401-412.

69. Rotondi M, Coperchini F, Chiovato L. 2013. CXCL8 in thyroid disease: from basic notions to potential applications in clinical practice. Cytokine Growth Factor Rev. 24: 539-546.

70. Pichert A, Schlorke D, Franz S, Arnhold J. 2012. Functional aspects of the interaction between interleukin- 8 and sulfated glycosaminoglycans. Biomatter 2: 142-148.

71. Zarogoulidis P, Katsikogianni F, Tsiouda T, Sakkas A,
Katsikogiannis N, Zarogoulidis K. 2014. Interleukin-8 and interleukin-17 for cancer. Cancer Invest. 32: 197-205.

72. Li Z, Chen L, Liu Q. 2015. Activation of CXCL-8 transcription by hepatitis E virus ORF-1 via AP-1. Mediators Inflamm. 2015: 495370.

73. Holtmann H, Winzen R, Holland P, Eickemeier S, Hoffmann E, Wallach $\mathrm{D}$, et al. 1999. Induction of interleukin-8 synthesis integrates effects on transcription and mRNA degradation from at least three different cytokine- or stress-activated signal transduction pathways. Mol. Cell. Biol. 19: 6742-6753.

74. Cucinotta M, Visalli M, Aguennouz M, Valenti A, Loddo S, Altucci L, et al. 2008. Regulation of interleukin-8 gene at a distinct site of its promoter by CCAAT enhancer-binding protein homologous protein in prostaglandin E2-treated human T cells. J. Biol. Chem. 283: 29760-29769.

75. Nozell S, Laver T, Patel K, Benveniste EN. 2006. Mechanism of IFN-beta-mediated inhibition of IL-8 gene expression in astroglioma cells. J. Immunol. 177: 822-830.

76. Gusella GL, Musso T, Bosco MC, Espinoza-Delgado I, Matsushima K, Varesio L. 1993. IL-2 up-regulates but IFNgamma suppresses IL-8 expression in human monocytes. J. Immunol. 151: 2725-2732.

77. Boost KA, Sadik CD, Bachmann M, Zwissler B, Pfeilschifter J, Muhl H. 2008. IFN-gamma impairs release of IL-8 by IL1beta-stimulated A549 lung carcinoma cells. BMC Cancer 8: 265.

78. Chen WC, Tseng CK, Chen YH, Lin CK, Hsu SH, Wang SN, et al. 2015. HCV NS5A up-regulates COX-2 expression via IL-8-mediated activation of the ERK/JNK MAPK pathway. PLoS One 10: e0133264.

79. Collins AS, Ahmed S, Napoletano S, Schroeder M, Johnston JA, Hegarty JE, et al. 2014. Hepatitis C virus (HCV)-induced suppressor of cytokine signaling (SOCS) 3 regulates proinflammatory TNF-alpha responses. J. Leukoc. Biol. 96: 255-263.

80. Kang SM, Won SJ, Lee GH, Lim YS, Hwang SB. 2010. Modulation of interferon signaling by hepatitis $C$ virus non-structural 5A protein: implication of genotypic difference in interferon treatment. FEBS Lett. 584: 4069-4076.

81. Munir M, Zohari S, Belak S, Berg M. 2012. Doublestranded RNA-induced activation of activating protein-1 promoter is differentially regulated by the non-structural protein 1 of avian influenza A viruses. Viral Immunol. 25: 79-85.

82. Devhare PB, Desai S, Lole KS. 2016. Innate immune responses in human hepatocyte-derived cell lines alter genotype 1 hepatitis $\mathrm{E}$ virus replication efficiencies. Sci. Rep. 6: 26827.

83. Clark K, Plater L, Peggie M, Cohen P. 2009. Use of the pharmacological inhibitor BX795 to study the regulation and physiological roles of TBK1 and IkappaB kinase epsilon: a distinct upstream kinase mediates Ser-172 phosphorylation and activation. J. Biol. Chem. 284: 14136-14146. 
84. Shimada T, Kawai T, Takeda K, Matsumoto M, Inoue J, Tatsumi Y, et al. 1999. IKK-i, a novel lipopolysaccharideinducible kinase that is related to IkappaB kinases. Int. Immunol. 11: 1357-1362.

85. Hemmi H, Takeuchi O, Sato S, Yamamoto M, Kaisho T, Sanjo $\mathrm{H}$, et al. 2004. The roles of two IkappaB kinase-related kinases in lipopolysaccharide and double stranded RNA signaling and viral infection. J. Exp. Med. 199: 1641-1650.

86. Ortiz NE, Nijhawan RI, Weinberg JM. 2013. Acitretin. Dermatol. Ther. 26: 390-399.

87. Buccheri L, Katchen BR, Karter AJ, Cohen SR. 1997. Acitretin therapy is effective for psoriasis associated with human immunodeficiency virus infection. Arch. Dermatol. 133: 711-715.

88. Li P, Kaiser P, Lampiris HW, Kim P, Yukl SA, Havlir DV, et al. 2016. Stimulating the RIG-I pathway to kill cells in the latent HIV reservoir following viral reactivation. Nat. Med. 22: 807-811.

89. Horner SM, Gale M Jr. 2013. Regulation of hepatic innate immunity by hepatitis C virus. Nat. Med. 19: 879-888.

90. Gale M Jr, Foy EM. 2005. Evasion of intracellular host defence by hepatitis $C$ virus. Nature 436: 939-945.

91. Zhou X, Xu L, Wang W, Watashi K, Wang Y, Sprengers D, et al. 2016. Disparity of basal and therapeutically activated interferon signalling in constraining hepatitis $\mathrm{E}$ virus infection. J. Viral Hepat. 23: 294-304.

92. Dong C, Zafrullah M, Mixson-Hayden T, Dai X, Liang J, Meng J, et al. 2012. Suppression of interferon-alpha signaling by hepatitis E virus. Hepatology 55: 1324-1332.

93. Bode JG, Ludwig S, Ehrhardt C, Albrecht U, Erhardt A,
Schaper F, et al. 2003. IFN-alpha antagonistic activity of $\mathrm{HCV}$ core protein involves induction of suppressor of cytokine signaling-3. FASEB J. 17: 488-490.

94. Shuai K, Liu B. 2003. Regulation of JAK-STAT signalling in the immune system. Nat. Rev. Immunol. 3: 900-911.

95. Akhtar LN, Qin H, Muldowney MT, Yanagisawa LL, Kutsch O, Clements JE, et al. 2010. Suppressor of cytokine signaling 3 inhibits antiviral IFN-beta signaling to enhance HIV-1 replication in macrophages. J. Immunol. 185: 2393-2404.

96. Huang F, Yang C, Yu W, Bi Y, Long F, Wang J, et al. 2016. Hepatitis $\mathrm{E}$ virus infection activates signal regulator protein alpha to down-regulate type I interferon. Immunol. Res. 64: 115-122.

97. Nan Y, Yu Y, Ma Z, Khattar SK, Fredericksen B, Zhang YJ. 2014. Hepatitis $E$ virus inhibits type I interferon induction by ORF1 products. J. Virol. 88: 11924-11932.

98. Karpe YA, Lole KS. 2011. Deubiquitination activity associated with hepatitis $\mathrm{E}$ virus putative papain-like cysteine protease. J. Gen. Virol. 92: 2088-2092.

99. Skaug B, Chen ZJ. 2010. Emerging role of ISG15 in antiviral immunity. Cell 143: 187-190.

100. Frias-Staheli N, Giannakopoulos NV, Kikkert M, Taylor SL, Bridgen A, Paragas J, et al. 2007. Ovarian tumor domaincontaining viral proteases evade ubiquitin- and ISG15dependent innate immune responses. Cell Host Microbe 2: 404-416.

101. Sulea T, Lindner HA, Purisima EO, Menard R. 2005. Deubiquitination, a new function of the severe acute respiratory syndrome coronavirus papain-like protease? J. Virol. 79: 4550-4551. 